\title{
LA FAMILIA DE SANTO TORIBIO ALFONSO DE MOGROVEJO (SIGLOS XIV-XVII)
}

\author{
Margarita TORRES SEVILLA \\ Universidad de León
}

RESUMEN: Hemos tratado de actualizar un trabajo anterior nuestro en el que recomponíamos la estructura de parentesco, ascendente y lateral, de Santo Toribio de Mogrovejo. En las páginas siguientes reconstruiremos la línea dimanada del Maestre de Campo, Gobernador de Chile y General de la Armada de los Mares del Sur Don Francisco de Quiñones, cuñado del santo. Una dinastía al servicio de la Corona española cuyos descendientes habrán de dividirse en dos ramas, la hispana y la americana, ejemplificando un modelo nobiliario común en el siglo XVII.

PALABRAS CLAVE: Santo Toribio de Mogrovejo, Francisco de Quiñones, Maestre de Campo, Chile, Armada de los Mares del Sur, nobleza, siglo XVII.

ABSTRACT: With this article we try to update a previous work about Santo Toribio de Mogrovejo's family and ancestors. The main point is focused on Maestre de Campo Francisco de Quiñones, his brother-in-law, who was governor of Chile and General. His descendants were divided in two different lines: Indian and Spanish ones. We study this familiar environment, common in Spanish nobility in XVII century.

KEYWORDS: Santo Toribio de Mogrovejo's, Francisco de Quiñones, Maestre de Campo, Chile, General, Spanish nobility, XVII century.

Han transcurrido más de quince años desde que vio la luz un primer avance nuestro sobre el entorno familiar del prelado de Lima ${ }^{2}$. Desde entonces, nuevas propias investigaciones subsiguientes y un mayor monto de información genealógica fuerzan a retomar este tema para ofrecer a la comunidad científica una

${ }^{1}$ Recibido el 13 de septiembre y aceptado para su publicación el 22 de septiembre de 2009.

2 TorRes Sevilla, M. (1992), «Los Quiñones, señores de Quintanilla de Sollamas y del solar antiguo de San Román de los Caballeros, conquistadores y gobernadores del virreinato del Perú», Astorica 11, pp. 157-190. 
revisión en algún aspecto, ampliación en la práctica totalidad, de la parentela de Santo Toribio. Una estirpe que nos llevará a establecer lazos extensos que, incluso, atrapan en su lazo a Cristóbal Vaca de Castro y a otros personajes significativos de la historia del Virreinato del Perú ${ }^{3}$. Un recorrido que, necesariamente, revelará una forma de vida nobiliaria que es directa heredera de los modos de comportamiento y de las solidaridades propias de las redes de parentesco, mayor y menor, de la aristocracia leonesa y castellana.

Como es bien conocido, la familia del santo pertenece a una élite local de servicio cuyas raíces más antiguas no superan los siglos bajomedievales, pues no pueden seguirse más allá de las guerras civiles entre Pedro I y Enrique II que culminaron en 1369 con el cambio dinástico en Castilla que supuso la entronización del conde de Trastámara.

Es a partir de entonces, segunda mitad del siglo XIV, cuando nuevas estirpes empujan hacia arriba del sistema piramidal nobiliario mientras que otras, de semejante antigüedad, pierden peso específico y quedan relegadas a posiciones secundarias en la corte o, incluso, ancladas a lugares menores, señoríos de escasa relevancia, o han de imbricarse en el sistema de solidaridades de sus parientes mayores. Tal sería el caso de los Muñoz-Cerón de Mayorga, de los Quiñones de la Casa de Sena o de los Villapadierna, sin ir más lejos. Linajes todos ellos directamente relacionados más tarde con Toribio de Mogrovejo y su grupo familiar.

Junto a estos vectores de comportamiento que permiten la supervivencia, el mantenimiento, de estirpes segundonas durante las últimas etapas del Medioevo, hemos de sumar otro elemento para una mejor comprensión del sistema aristocrático castellano y leonés que cruza hacia la Edad Moderna. Nos referimos al servicio de armas.

Durante siglos, la lucha contra el Islam hispano supuso una fuente de ingresos y un motor de ascenso para los caballeros. La participación en la conquista del Guadalquivir en tiempos de Fernando III, por ejemplo, permitió una salida más que honorable a miembros menores de las grandes casas, como los Ponce de León o los Guzmanes leoneses, por mentar dos ejemplos. Así mismo, la frontera granadina, vigente y activa hasta 1492, significó una tierra de promisión en la que buscar fama, honor y riquezas que garantizasen un matrimonio ventajoso y el definitivo reconocimiento.

${ }^{3}$ Sobre el virrey Vaca de Castro véase: Paniagua, J. y Viforcos, Ma I. (1991), El leonés don Cristóbal Vaca de Castro, Madrid: Hullera Vasco-Leonesa. 
Culminada la conquista el mismo año del Descubrimiento de América, la etapa que se inicia al filo del cambio de siglo y que alcanzará hasta los Austrias Mayores, permitió a la nobleza menor continuar en nuevas fronteras el modelo de comportamiento aprendido durante generaciones y siglos. América, pues, no se diferenciaba conceptualmente demasiado de Granada o de los taifas en tanto en cuanto a través de la probanza personal, ya con las armas, ya con el servicio más pacífico del gobierno, se podían escalar puestos en el organigrama social existente. Cortés o Pizarro son dos ejemplos paradigmáticos, pero no los únicos, ni siquiera los más exitosos.

Por todo ello, es fácil comprender hasta qué punto un nombramiento en Indias, o el anuncio de nuevas conquistas, suponían unas ventanas abiertas que no podían dejarse escapar sin aprovecharlas pues, en caso de lograr fortuna, este éxito suavizaría el camino a otros miembros de la estirpe que acudieran a la llamada del pariente a quien hubiera sonreído la suerte.

Estas formas, medievales en su planteamiento, tendían a reproducir en Indias el viejo sistema del pariente mayor que articulaba una red en torno suyo que comprendía tanto a sus familiares más directos, hermanos y primos, como a los vinculados por parentesco transversal más alejado, sobre los que sofirmar un modelo de poder que garantizase la supervivencia y aún la consolidación de la malla aristocrática. Una vez lograda, reclamar elementos anteriores presentes en otros episodios previos a manera de ancestros suponía una forma de salvar el último escollo para lograr el objetivo de confirmarse como élite: no ser vistos por los descendientes de los primeros conquistadores como ajenos o advenedizos, sino como miembros de una misma causa, lo que permite crear, sobre esa aceptación definitiva, nuevos tentáculos clientelares quienes son semejantes.

Todos estos patrones aparecen reflejados con claridad en el núcleo familiar que rodeará a Toribio de Mogrovejo, como tendremos ocasión de atestiguar a través de las páginas que se siguen. Comenzaremos por los precedentes.

\section{LA PARENTELA QUIÑONES Y MOGROVEJO AL SERVICIO DE LA CORONA EN INDIAS}

Si el referente americano más inmediato se llama Cristóbal Vaca de Castro, esposo de María Magdalena de Quiñones y primo del cuñado de Santo Toribio, Francisco de Quiñones Mogrovejo, no es menos cierto que, junto con el señor de Izagre, hallaremos otros caballeros vinculados por linaje directo o transversal con el arzobispo de Lima y su núcleo más cercano. 
Así, en las Crónicas del Perú, aparecerán mentados Antonio de Quiñones, vecino de Cuzco y natural de León, pizarrista hasta la médula que se enfrenta a Vaca de Castro acompañado de su primo Suero de Quiñones, del mismo origen, mientras que en el partido del virrey figura otro primo de ambos Quiñones de nombre Alonso ${ }^{4}$.

También en los primeros momentos de la conquista nos figuran dos miembros del linaje directo que nos ocupa: los capitanes Juan Núñez de Prado y Juan Mogrovejo de Quiñones (véase el Esquema Genealógico 1).

Juan Mogrovejo de Quiñones y Prado, sin pretenderlo fue un motivo de enfrentamiento entre su familia y el virrey Vaca de Castro. Enviado por Francisco Pizarro para domeñar a las tropas incas desde Lima por vía de Jauja, fue sorprendido con sus hombres en Angoyacu, donde falleció de resultas del combate con los indios ${ }^{5}$. Sus bienes fueron heredados por su madre, Brianda de Prado y Quiñones, esposa de Gonzalo Alfonso Mogrovejo, quien pleitea con Cristóbal Vaca de Castro por la entrega de una cierta cantidad de dinero que le pertenece y el gobernador no le ha liberado ${ }^{6}$. Al no haber generado descendencia, sus méritos pasaron a formar parte del haber tanto de Francisco de Quiñones, cuñado de Santo Toribio, como de sus propios hijos, como tendremos ocasión de comprobar.

Respecto a Juan Núñez de Prado, también vinculado por linaje, formó parte del grupo de los primeros conquistadores de Perú y pronto abandonó el servicio de Gonzalo Pizarro para sumarse al partido que defendía el Licenciado La Gasca quien, en 1549, recomienda a este noble, del que nos informa ejerce como alcalde de las minas de Potosí, para que pase a ocuparse del poblamiento de Tucumán ${ }^{7}$.

A estos ya mencionados podríamos sumar algunos miembros menores, pero ya más alejados en parentesco al tronco nobiliario que nos ocupa, por lo que consideramos oportuno cerrar este apartado que nos permitirá cruzar el umbral hacia el que nos llevará de la mano hacia aquellos otros caballeros, capitanes de

\footnotetext{
${ }^{4}$ FERNÁNDEZ De CóRDOBA, D. (1963), Crónicas del Perú: primera y segunda parte de la historia del Perú que se mando a escribir a Diego Fernandez, 5 vols., Madrid: Biblioteca de Autores Cristianos, II, p.94, V, p. 24.

5 Sus servicios a la corona se describen en las informaciones de Luis de Quiñones Mogrovejo, sobrino de Santo Toribio, datadas en 1606 (A.G.I., Lima, 217, N. 12).

${ }^{6}$ Duraron los problemas de herencia más de quince años, pues el capitán perdió la vida en 1536 y su madre todavía mantenía activo el pleito en 1550 y 1552, tal y como consta en la documentación conservada en el Archivo General de Indias (A.G.I., Justicia, 1164, N. 2. R. 1 y Patronato, 281, N. 1. R. 2).

${ }^{7}$ A.H.N., Diversos-Colecciones, 23, N. 35.
} 
armas y oficiales, algunos incluso cruzados de la orden de San Juan, que sumarán la cotización de méritos de la estirpe centro de nuestro estudio. Nos referimos, por supuesto, a Antonio de Mogrovejo y Quiñones -Esquema Genealógico 1-, hermano de Francisco, primo de Santo Toribio, cuya vida conocemos gracias a los memoriales e informaciones para obtener hábitos de Órdenes Militares realizados por sus sobrinos Luis y Antonio de Quiñones Mogrovejo, quienes nos aclararán que gastó su existencia en servicio de la corona falleciendo preso en Berbería después de crueles prisiones y sin generar prole, por lo que, como en los casos anteriores, engrosará el capítulo de méritos de sus parientes más cercanos ${ }^{8}$.

\section{LOS ORÍGENES DE LOS QUIÑONES-MOGROVEJO}

Siendo ambos cuñados primos entre sí, nos referimos a Santo Toribio y a Francisco de Quiñones, realizar un somero recorrido por el linaje paterno del arzobispo supondrá componer el esquema genealógico del general y gobernador de Chile al mismo tiempo (véase Esquema 2).

Las referencias más antiguas de esta estirpe, que podemos seguir sin equívoco generacional y de forma clara, nos llevan hasta finales del s. XV de la mano del primer antepasado conocido del santo: Gonzalo Muñoz. Desposado con Francisca Cerón, fue regidor de Mayorga, villa en la cual se asientan las raíces de los Mogrovejo apenas si una generación después y por matrimonio. Su mujer, Francisca, era pariente de Ruy Díaz Cerón, corregidor de Ponferrada a comienzos del reinado conjunto de Juana de Castilla y Carlos I. Familia de funcionarios de la corona, los Cerón, entroncados con los Osorio de la casa de los marqueses de Astorga, cuenta con ilustres parientes entre los que no será el menos relevante el capitán general de Canarias Pedro Cerón 9 .

Hija del regidor de Mayorga será Beatriz Muñoz Cerón, que desposará con Juan Alfonso de Mogrovejo, bachiller, miembro de una familia de caballeros ilustrados cuyo paso por la Universidad será una constante, como acontecerá en los casos de Francisco de Quiñones y de Toribio de Mogrovejo, sin olvidarnos del Doctor en Leyes Juan Mogrovejo. Enraizados en Mayorga, allí dispondrán su capilla enterramiento, al igual que ocurrirá con los Villapadierna, en el convento de San

8 Informaciones de Luis de Quiñones Mogrovejo (1606), caballero de Alcántara, hijo de Francisco Quiñones y Grimanesa Mogrovejo, hermana del Arzobispo (A.G.I., Lima, 217, N.12).

${ }^{9}$ A.G.S., Cámara de Castilla, Diversos, Leg. 13, docs. 11, 21 y 57. 
Francisco, lo que dará origen a algunos roces y choques entre ambas estirpes que todavía se alargarán en el tiempo hasta bien avanzado el s. XVI ${ }^{10}$.

Del bachiller Mogrovejo surgirán dos ramas destinadas a encontrarse: la primera, en la cabeza de Jorge Alfonso de Mogrovejo, la segunda, en la de Gonzalo Alfonso de Mogrovejo (véase Esquema Genealógico 2). El primero desposará con Violante Coco y de dicha unión nacerá Luis Alfonso de Mogrovejo, marido de Ana de Robledo y Morán, padres ambos de nuestro Santo y de otros cuatro hijos, entre los que se incluye Grimanesa Mogrovejo. Respecto de la segunda línea, Gonzalo Alfonso de Mogrovejo se une a la dama Brianda de Prado y Quiñones, hija del señor de la Casa de Albires, descendiente de los Quiñones de Sena. De este matrimonio nos constan dos hijos: Juan Mogrovejo de Quiñones y Prado, capitán muerto en Indias, y Beatriz de Mogrovejo y Prado, mujer del señor de Zalamillas Pedro de Villapadierna y madre de Juan, Antonio y Francisco de Quiñones.

Esta separación en dos de los Mogrovejo de Mayorga será recosida con el matrimonio de Francisco de Quiñones Villapadierna Mogrovejo y Prado y Grimanesa Mogrovejo Robledo, hermana de Santo Toribio. Una unión que articulará el resto de nuestro trabajo. No queremos, sin embargo, dejar pasar este momento sin referirnos a los otros hermanos del arzobispo Mogrovejo. Nos referimos a Lupercio, que desposará a María de Quiñones, matrimonio del que descienden los señores de Quintanilla de Sollamas, estirpe a la que pertenece Luis Osorio de Quiñones, o Quiñones Osorio, gobernador de Tucumán.

A estas alturas no resulta necesario presentar en el panorama nobiliario leonés a la estirpe Quiñones, surgida como una escisión de los Álvarez de Asturias, Merinos Mayores de León y Asturias, Adelantados Mayores y señores de Luna, Sena y otros lugares a caballo entre León y el Principado. Consolidada su posición con la concesión real a la línea primogénita del título condal de Luna, su dominio territorial, una extensión suficiente como para que, en el tránsito a la Edad Moderna, podamos calificar a esta familia de la aristocracia leonesa como la primera en prestigio, alianzas, señoríos y sangre entre las asentadas en la hoy provincia de León. Sus redes de parentesco, hábilmente tejidas por Diego Fernández de Quiñones y su esposa María de Toledo, padres del célebre Suero de Quiñones, el de la hazaña del Passo Honroso, enlazan a los Almirantes de Castilla, condes de Benavente, marqueses de Astorga, condes de Valencia de Don Juan,

10 Así, en 1574 todavía se mantiene el litigio entre sus descendientes, Bernardino de Villapadierna y Comontes, señor de Zalamillas, y Francisco de Mogrovejo, natural de Mayorga, y sus respectivas consortes, sobre el patronazgo de la capilla mayor y dos colaterales del referido convento de San Francisco de Mayorga (A.R.CH.V., Pl. civiles, Fernando Alonso, caja 1270.0001). 
vizcondes de Palacios de la Valduerna y aún a otras casas de semejante poder y afirmación en la corte de los últimos Trastámaras ${ }^{11}$.

En torno a la rama principal, conocida como Quiñones de Luna, orbitarán otras menos relevantes, como los Quiñones señores de Sena, Alcedo, o los mismos de Quintanilla de Sollamas, tan cercanos como tendremos ocasión de apreciar a Santo Toribio. Pues bien, pertenecientes a la Casa de Sena los antepasados del general Francisco de Quiñones, cuñado del arzobispo Mogrovejo, su filiación queda aclarada en el Esquema Genealógico 1 que acompaña a este texto, al que remitimos al lector antes de pasar a ocuparnos de su persona.

\section{EL ENTORNO INMEDIATO: EL MAESTRE DE CAMPO FRANCISCO DE QUIÑONES, GOBERNADOR DE CHILE Y GENERAL DE LA ARMADA DE LOS MARES DEL SUR}

Francisco de Quiñones, cuñado de Santo Toribio -véanse Esquemas Genealógicos 1 y 2-, pertenece a una rama menor linaje Quiñones. De hecho, por línea agnática ni siquiera se le puede considerar miembro, pues fueron sus padre el señor de Zalamillas, Pedro de Villapadierna, y Beatriz de Mogrovejo y Prado, quedando relegado el entronque Quiñones a la posición de su bisabuela, Catalina de Quiñones, hija del señor de Sena, esposa de Rodrigo de Prado y Vega, señor de Albires.

Formaban todos ellos parte de la nobleza segundona leonesa de la montaña y de Tierra de Campos, una aristocracia menor que ofreció algunos personajes relevantes al servicio de la administración, como el mentado Vaca de Castro o los ya aludidos ut supra. Esta posición más bien apartada de toda esfera real de poder forzó a la carrera de las armas a varios de sus miembros, entre ellos el propio Francisco de Quiñones, cuya trayectoria vital queda reflejada con minuciosidad preciosista en varios documentos que debemos a su mano y a las de sus vástagos varones, que desearán auparse sobre sus hombros para lograr el ansiado hábito de

${ }^{11}$ Sobre la misma, véanse: Álvarez Álvarez, C. (1982), El condado de Luna en la Baja Edad Media, León: Celarayn; QuiÑones De León, F. (Marqués de Alcedo y San Carlos) (1918 y 1925), Los Merinos Mayores de Asturias y su descendencia del apellido Quiñones, 2 vols., Madrid: Sociedad Española de Artes Gráficas; TorRes SEVILlA, M. (1999), «Los orígenes del linaje Quiñones: una hipótesis de trabajo», La nobleza peninsular en la Edad Media. VI Congreso de Historia Medieval organizado por la Fundación "Sánchez-Albornoz", León: Unigraf, pp. 569-580; TORRES SEVILLA, M. (2000), «Nobleza asturleonesa en la conquista de Sevilla: Froilaz, Alvarez de Asturias y Quiñones», Sevilla, 1248. Congreso Internacional conmemorativo del 750 aniversario de la conquista de Sevilla por Fernando III, Sevilla, 23-27 de noviembre de 1998, Madrid: Centro de Estudios Ramón Areces, pp. 897906. 
Alcántara en ambos casos, una ratificación de cara a la sociedad tanto indiana como de la Península, de la nueva posición social alcanzada por ellos ${ }^{12}$.

Nacido en 1540, inició su camino a través del estudio en Salamanca, abandonando pronto las letras por las armas, ya que sabemos que pasó a Nápoles con su hermano Antonio, caballero de San Juan, donde destacó en varias empresas militares para caer prisionero en la triste jornada de los Gelves (1559), al igual que su hermano. Cautivo del turco, consiguió ser liberado, fortuna que no acompañó a Antonio, que murió en las temibles cárceles de Constantinopla ${ }^{13}$.

De vuelta a España, contraerá matrimonio hacia 1574 con su prima Grimanesa Mogrovejo, residiendo el matrimonio en esa villa de Campos durante algunos años durante los cuales el caballero ejercerá como familiar del Santo Oficio y nacerán sus tres hijos mayores: Antonio, Mariana y Beatriz. Con ellos y su esposa embarcará con destino a Perú en la flota que parte en otoño de 1580, al servicio del nuevo arzobispo de aquellas tierras: su propio cuñado, Toribio Alfonso de Mogrovejo $^{14}$.

Conocedor de la valía como militar de Francisco de Quiñones, pronto es nombrado Maestre de Campo, Comisario General de Caballería y, poco después, General de la Armada de los Mares del Sur, todo ello gracias al apoyo del virrey Martín Enríquez de Almansa, que continuará prestándoselo durante años ${ }^{15}$.

El propio conde del Villar, virrey del Perú, dirá de él durante su nombramiento como corregidor de la Ciudad de los Reyes que, para evitar discordias civiles, optó por elegir a este caballero ya que en su persona convergen notables cualidades, no siendo la menor su nobleza de carácter, su servicio de armas previo y su cortesía, amén de su remarcado y cercano parentesco con el arzobispo Mogrovejo ${ }^{16}$.

${ }^{12}$ A.G.I., Lima, 217, N.12; A.G.I., Patronato, 138, R.6; A.H.N., O.O.M.M., Alcántara, Exp. 1246 Y 1252.

13 Así lo describe el arzobispo Mogrovejo en alguna de sus cartas al rey de 1591 (A.G.I., Patronato, 248, R.10 y 21).

${ }^{14}$ A.G.I., Pasajeros, L.6, E.3495.

15 M. TORRes Sevilla (1992), «Los Quiñones, señores de Quintanilla de Sollamas y del solar antiguo de San Román de los Caballeros, conquistadores y gobernadores del virreinato del Perú», Astorica 11, pp. 157-190, pp. 164-165.

16 “...En la Ciudad de los Reyes habia dos alcaldes ordinarios, los cuales se nombraban por los regidores de dicha ciudad. Entendí que sobre ello había, de algunos años a esta parte, muchas discordias....y se iban formando dos bandos...que...se extendian por la ciudad... Y habiendo noticia de que Don Francisco de Quiñones es muy buen caballero y ha servido a S. M. en la guerra, en diversas partes, y que en su persona concurrían todas las cualidades que se requerian para 
Corregidor y Justicia Mayor de Lima. Su vida trascurre tranquilamente. Allí le nacerán dos nuevos hijos, María y Luis y recibirá nuevas mercedes del conde del Villar, como sus nombramientos de corregidor sobre las villas de Cañete, Arnedo y Chancay. Sólo la llegada del nuevo virrey, García de Mendoza, trajo alguna desazón a su existencia, ya que conocidos fueron en su tiempo los enfrentamientos sonoros entre el nuevo representante de la corona y el curador de las almas Toribio Alfonso de Mogrovejo, lo que obligará a posicionarse junto a su cuñado a Francisco de Quiñones. Llega este choque en el peor de los momentos para el militar, ya que se negociaba en la corte, a propuesta realizada ante el Consejo de Indias, la posibilidad de concederle un hábito en atención a sus servicios, distinción que no llega ante la falta de acuerdo del virrey ${ }^{17}$.

Este alineamiento provocará las iras del virrey, que no duda en apresarle y aún recluirle en una nave en el puerto de El Callao, como instrumento de coerción para conseguir doblegar la voluntad del arzobispo, que finalmente cede, temeroso de la mala salud del Quiñones y de que se cumpla la nueva amenaza de Mendoza y sea encarcelada su hermana Grimanesa ${ }^{18}$.

La llegada de un nuevo virrey a Perú, Luis de Velasco, sumada a la inquietante situación en el territorio araucano, donde los indios llegaron a dar muerte al gobernador Loyola, a quien degollaron en $1599^{19}$, trajeron un nuevo cambio en la vida de Quiñones que será nombrado gobernador de Chile y a quien Velasco concede una tropa de 400 hombres que, desde Lima, partirán a sofocar la rebelión. La escasez de soldados, las guarniciones diezmadas, la penuria del ejército español allí acantonado, forzaron al general a invertir 12.000 ducados de su hacienda personal para vestir y armar a los hombres bajo sus órdenes. Una suma que, pronto, se advertirá escasa y que supondrá un desembolso global de 100.000 ducados para las arcas Quiñones, cantidad tal vez exagerada en los memoriales de sus hijos pero que, en cualquier caso, nos aproxima a la nueva posición de prestigio y riqueza alcanzada en Indias.

Acompañado por su hijo mayor, Antonio, en calidad de capitán y como su mano derecha, quiso pasar y poblar Valdivia pero hubo de limitarse a una guerra

ello...aunque temí no fuese de algún inconveniente ser cuñado del arzobispo...le nombre por corregidor..." (HANKE, L. y RODRÍGUEZ, C. (1978), Los virreyes españoles en América durante el gobierno de la Casa de Austria. Perú, I, Madrid: Atlas, p. 198).

17 A.G.I., Lima, 1, N. 118.

18 Rodríguez Valencia, V. (1957), Santo Toribio de Mogrovejo, organizador y apóstol de Suramérica, II, Madrid: C.S.I.C., pp. 148-49.

${ }^{19}$ A.G.I., Patronato, 228, R. 18. 
defensiva y de posiciones. Durante el invierno alzó el cerco de Engol y La Imperial, que más tarde perdió, y forzó a los indígenas a cruzar el río Bio-Bio. Cercano en el fuerte Arauco, consiguió deshacer la amenaza india y liberar la plaza aunque, durante todo este largo proceso de luchas, su salud, ya endeble, sufrió nuevos golpes. La guerra de Chile cercenará sus esperanzas. La escasez, la cercanía repetida de la muerte, le llevará en diciembre de 1600 a regresar y abandonar su cargo en manos de otro gobernador, Alonso de Rivera ${ }^{20}$. Dos años después, en 1602, acusado de mal gobierno en Chile por la corte de España, decide enviar a la Península a su primogénito Antonio, con el único propósito de limpiar su honor. En 1606, Francisco de Quiñones fallece en Indias ${ }^{21}$, no sin antes no haber negociado los matrimonios de sus hijas, María y Mariana, con caballeros del funcionariado en Indias, tal y como tendremos ocasión de analizar más adelante, y de haber colocado en la mejor de las posiciones posibles a sus dos vástagos varones, Antonio y Luis, para la consecución del hábito de una orden militar -será la de Alcántara- que a él se le negó por la animadversión del virrey Mendoza.

\section{LOS HIJOS DE FRANCISCO DE QUIÑONES: LA DIVISIÓN DE LA FAMILIA ENTRE LA RAMA INDIANA Y LA ESPAÑOLA}

Cinco fueron los hijos que sobrevivieron nacidos del matrimonio entre el Maestre de Campo Francisco de Quiñones y Grimanesa Mogrovejo. Tres de ellos vieron la luz en España, Antonio, Mariana y Beatriz, los dos últimos en Perú: Luis y María.

Antonio de Quiñones, primogénito de esta unión, es apenas un muchacho cuando cruza el Altántico acompañando a sus padres. Educado, al igual que su hermano menor Luis, a la sombra protectora del arzobispo, estudiará en el colegio limeño de San Martín. Junto a su padre servirá a la Corona en las luchas en Chile, tal y como consta en su propio memorial. Capitán y Teniente de General, retorna a Lima apenas su padre abandona la gobernaduría de Chile para embarcarse con destino a España con el único fin de limpiar ante el Consejo de Indias la imagen de su progenitor, mancillada por una acusación de mal gobierno en las tierras araucanas. En 1602 abandonará a su familia, asentándose primero en Mayorga, donde recoge parte de la herencia de los Mogrovejo, y, finalmente, en Medina del

${ }^{20}$ A.G.I., Patronato, 228, R. 17; 248, R. 30; 228, R. 1; 227, R. 37; 228, R. 19. A G.I., Lima, 214, N. 15.

${ }^{21}$ Véase el memorial de su hijo Luis de Quiñones ya aludió en nota como fuente primera. A ella podríamos sumar las referencias procedentes de la propia descripción de sus méritos y servicio realizada en 1606 por la viuda del general Francisco de Quiñones, doña Grimanesa Mogrovejo, y que se contiene en: A.G.I., Patronato, 143, N. 1, R. 2. 
Campo, donde reside en el momento de la concesión del hábito de Alcántara en $1609^{22}$.

Desposó en dos ocasiones, ambas en España. La primera, con Agustina Cabeza de Vaca y Montalvo, hija del caballero Juan de Briones Cabeza de Vaca, alcaide de los palacios y casa real de Medina del Campo ${ }^{23}$, de la que no dejó descendencia. La segunda, con Catalina de Ulloa, miembros de una reconocida familia de Tierra de Campos, con quien procreará a su único vástago varón: Victoriano de Quiñones, con quien se desdibuja la imagen de la familia perdiendo a un tiempo relevancia e interés en beneficio de las otras ramas de la estirpe Quiñones y Mogrovejo.

Por lo que se refiere a Beatriz de Prado y Quiñones, hija del matrimonio Francisco de Quiñones Villapadierna-Grimanesa Mogrovejo, ingresó muy joven en el convento de Santa Clara de Lima, fundado por su tío Santo Toribio, lugar donde se custodian la mayor parte de sus reliquias. Allí profesará hasta su muerte, en plena juventud, pues fallece en $1609^{24}$.

Mariana de Quiñones, o de Guzmán y Quiñones como optó por ser llamada, juega el papel más relevante de la familia en Indias. Vuelto a España Antonio, profesa Beatriz, al poco tiempo fallecido su otro hermano Luis, tanto ella como María, la menor de las hijas de Grimanesa Mogrovejo y Francisco de Quiñones, pasarán el resto de sus vidas en Perú, afianzando la posición de sus maridos respectivos y asegurando la pertenencia a la trama de poder funcionarial del virreinato para sus descendientes. Mariana casó también en dos ocasiones, la primera con Martín de Soto, del que le nació un varón llamado Diego de Soto y Quiñones, que cruzará el Océano de regreso a España asentándose en Medina del Campo, como su tío Antonio ${ }^{25}$. Viuda joven, enlazará su vida con Juan de Loaysa Calderón, Oidor de la Audiencia de Charcas y luego de la de Lima durante veinte años (1605 a 1625) ${ }^{26}$. Natural de Trujillo, cruzó a Perú en 1605, un año después de su nombramiento ${ }^{27}$. Hijo de estos será Pedro de Loaysa y Quiñones, Alguacil

${ }^{22}$ A.H.N., O.O.M.M., Alcántara, exp. 1252.

23 A.R.CH.V., Pl. civiles, Fernando Alonso, Caja 1186.0001.

${ }^{24}$ M. TORRes SEVILla (1992), «Los Quiñones, señores de Quintanilla de Sollamas y del solar antiguo de San Román de los Caballeros, conquistadores y gobernadores del virreinato del Perú», Astorica 11, pp. 157-190, p. 169.

25 A.H.P.L., Protocolos de Gudino de Valcárcel, caja 9511, s.f.

${ }^{26}$ Familia, la de los Loaysa Calderón de Trujillo, que cuenta en su haber con varios caballeros cruzados de diversas Órdenes Militares, como Pablo de Loaysa Calderón, que consiguió el hábito de San Juan en 1554 (A.H.N., O.O.M.M., San Juan de Jerusalén, exp. 23077).

27 A.G.I., Contratación, 5295, N. 1 y Contratación, 5792, L.2, F. 385V a 386V. 
Mayor de Potosi ${ }^{28}$, entre otros puestos desempeñados. Desposó Pedro con una dama peruana, Antonia Gregoria de Esquivel y de la Cueva, cuya dote todavía enfrentaba al marido con la familia de su mujer en fecha tan avanzada como $1659^{29}$. Tanto Mariana de Guzmán y Quiñones como su hijo Pedro de Loaysa, tratarán de hacerse con la mayor cantidad posible de los bienes de Quiñones y Mogrovejos, iniciándose un largo proceso de enfrentamientos entre ambos y uno de sus parientes y primos, Suero de Quiñones, del que nos ocuparemos en breve. Su muerte, ya en la ancianidad, le permitió una larga existencia de ambición que ha de convertirla en el blanco directo de aquellos miembros de su familia que regresaron a España. La separación entre ellos y la dama marcará una ruptura definitiva en el seno de la estirpe.

De María de Quiñones Mogrovejo sabemos que matrimonió con un miembro de la oligarquía indiana de Perú: Nicolás Mendoza de Carvajal o Carvajal de Mendoza, que de ambas maneras aparece recogido su nombre en los actos jurídicos coevos al matrimonio. De este noble, que fue capitán en Lima y caballero del hábito de Santiago desde 1608, conocemos que a través de su parentela y antepasados guardaba estrecha relación de generaciones con Indias ${ }^{30}$. Natural de la Ciudad de los Reyes, su padre, D. Alonso de Vargas Carvajal, caballero de Alcántara, aunque nacido en Trujillo (España), desde fecha temprana sirvió al otro lado del Océano, donde llegó a desempeñar el cargo de Gobernador y Capitán General de Cartagena, siendo sus méritos suficientemente voluminosos para apoyar el ascenso social de sus vástagos. Por su parte, la madre de Nicolás Mendoza Carvajal, María Dávalos, ya era indiana de nacimiento, pues vio la luz en Perú, circunstancia no infrecuente entre los miembros de esta familia. El abuelo materno de nuestro protagonista, D. Nicolás de Ribera, natural de Olvera en España, participó en la conquista de Perú junto a Pizarro, jugando un destacado papel en esta empresa y desposando allí con Elvira Dávalos, nacida en el tránsito de sus padres desde la isla de la Española hacia tierra firme ${ }^{31}$. Como se puede apreciar, de

${ }^{28}$ López De Caravantes, F. (1987), Noticia general del Perú, II, Madrid: Atlas, p. 141 y I, p. 182.

29 A.G.I., Pleitos Audiencia de Lima, Escribanía, ,508B.

${ }^{30}$ Los datos genealógicos que se incorporan a continuación proceden de su expediente para cruzarse caballero de Santiago (A.H.N., O.O.M.M., Caballeros de Santiago, Exp. 5161) así como de la documentación generada por su padre y abuelo y que se custodia en el Archivo de Indias (A.G.I., Patronato, 139, N.2 R1). Ambos documentos fundamentan su estirpe sobre datos aportados entre 1602 y 1608.

${ }^{31}$ Tal vez sorprenda los usos onomásticos, tan alterados, pero ni siquiera la abuela materna de Nicolás de Mendoza Carvajal portaba los apellidos propios agnáticos, ya su padre, natural de Soria, se llamaba García de Solier y su madre, parida en Andújar, portaba el nombre de Leonor de Valenzuela. 
nuevo los familiares más cercanos del santo enlazan sus vidas a miembros de la élite indiana con notoria hidalguía en España, reconocida con hábitos de Órdenes Militares, tal es el caso que ahora nos ocupa.

Finalmente, el quinto de los hijos y segundo de los varones, Luis de Quiñones Mogrovejo, nació en Perú, al igual que María ${ }^{32}$. Durante años cursó estudios en Lima, en el colegio de San Martín. Heredero de la biblioteca de su tío, Santo Toribio de Mogrovejo, pronto se doctoró en Derecho Canónico por la Universidad de San Marcos de Lima, momento en el que comienza su verdadera carrera funcionarial ya que obtiene de la Corona plaza de oidor de Quito en 1610, aunque solicitó, cuatro años antes, semejante honor en las de Lima y Panamá también, que acompañó de un oportuno memorial de méritos en el que recogía con minuciosidad los de su progenitor, Francisco de Quiñones ${ }^{33}$. Al servicio del rey falleció pocos años más tarde (1618), quedando por única heredera de su patrimonio su madre Grimanesa Mogrovejo, que solicita al marqués de Guadalcázar, virrey del Perú, que se le haga justicia y se le entreguen los bienes de su hijo en $1621^{34}$, una herencia que, como otras, acabará siendo gestionada por Mariana de Guzmán y Quiñones y los suyos.

\section{LOS OTROS QUIÑONES MOGROVEJO: LOS SEÑORES DE QUINTA- NILLA DE SOLLAMAS}

Quedaría para cerrar este trabajo referirnos a unos parientes de Santo Toribio que han generado cierta confusión genealógica. En su momento, nosotros mismos creímos encontrarnos ante un personaje sólo cuando abordamos la reconstrucción del esquema Mogrovejo-Quiñones ${ }^{35}$. Luis de Quiñones Osorio u Osorio de Quiñones, mantenía intereses americanos. Sus apellidos, cercanos al linaje leonés, no resultaban extraños habida cuenta del baile onomástico de esta estirpe en Indias, que genera cinco hermanos con diversos usos que oscilan entre un Guzmán de complejo rastreo hasta una recuperación del apellido Prado ya alejado agnáticamente. Es por ello que, sobre esta base, sumamos ciertas noticias

\footnotetext{
${ }^{32}$ Aunque su vida se presta a confusión con la de su primo y pariente, Luis Osorio de Quiñones, también un Mogrovejo, Señor de Quintanilla de Sollamas y gobernador de Tucumán, no debe caerse en el engaño. Discernir ambas figuras será objeto de las páginas que se siguen.

33 A.G.I., Lima, 217, N. 12.

${ }^{34}$ A.G.I., Patronato, 138, R. 6.

35 Nuestra confusión se fundamentaba en la identificación del Doctor Luis de Quiñones Mogrovejo -o Quiñones y Prado- con Luis de Quiñones Osorio - $\mathrm{u}$ Osorio de Quiñones, gobernador de Tucumán. Ambos de la misma generación vital y parientes cercanos, pues resultan ser primos tal y como hoy podemos documentar.
} 
documentales procedentes de los protocolos notariales conservados en el Archivo Histórico Provincial de León que coadyuvaron al error. Así Luis de Quiñones Osorio tuvo hijos naturales en Indias y legítimos con la dama española María Velázquez Arias, se vinculaba patrimonialmente por territorios semejantes a los Quiñones-Mogrovejo analizados. A ello hemos de añadir la onomástica de sus hijos entre los que consta una Lupercia, nombre de estirpe relacionado con los Mogrovejo (véase Esquema Genealógico 2) y, finalmente, las fechas no impedían una sucesión cronológica más o menos consecuente con la que se añadía el apelativo de tía y primo que, respecto a Mariana de Guzmán y a su hijo Pedro de Loaysa utilizaban los hijos de Luis Quiñones Osorio en los actos jurídicos que protagonizaban y de los que nos resta memoria escrita.

No quedamos entonces conformes por completo con el resultado de aquel primer abordaje de investigación emprendido en 1992 y proseguimos el rastreo de este supuesto único caballero hasta conseguir, a través de la documentación indiana y notarial leonesa, recomponer y separar las dos trayectorias vitales diferenciadas que surgían a cada paso.

De Luis de Quiñones Osorio, también conocido en los diplomas como Osorio de Quiñones, conocemos su filiación, pues es hijo de Lupercio de Mogrovejo y de María de Quiñones, hermano el primero de Santo Toribio de Mogrovejo y la segunda cercana por sangre a Francisco de Quiñones, lo que incrementó la confusión inicial. Podemos afirmar que pasó a formar parte del grupo de parientes a los que benefició el nombramiento del arzobispo de forma directa ya que, en 1596, recibió el título de tesorero de la Hacienda Real en Charcas, con 2.000 pesos de suelto ${ }^{36}$, y pasará a ocuparse de Potosí, llegando incluso a plantear ciertas problemas y potenciales soluciones acerca de los usos del hierro y del azogue ${ }^{37}$. Ese mismo año solicita licencia para cruzar el Atlántico sin su esposa, María Velázquez Arias quien, al encontrarse en avanzado estado de gestación, debe guardar reposo en Sevilla retrasando su viaje ${ }^{38}$. Tal vez arrepentido de su decisión, un par de años después ruega al monarca que le autorice a acudir de nuevo a España para buscarla a ella y a sus hijos y viajar juntos definitivamente a América, lo que acaece y se tiene por bien en $1599^{39}$, aunque no sin antes rendir cuentas de

\footnotetext{
${ }^{36}$ A.G.I., Contratación, 57923, L. 2, F. 221-222.

${ }^{37}$ A.G.I., Patronato, 238, N.1,R.10.

${ }^{38}$ A.G.I., Indiferente, 2103, N. 49.

${ }^{39}$ A.G.I., Indiferente, 2104, N. 121.
} 
sus labores en Potosí, hasta ese mismo año, al Doctor Hernando Arias de Ugarte y al contador Martín de Galarza ${ }^{40}$.

Su estancia en Indias no durará demasiado, pues regresa a León para hacerse cargo de los mayorazgos de su linaje y del señorío de Quintanilla de Sollamas y de la así llamada Casa y Solar antiguo de los Quiñones de San Román de los Caballeros ${ }^{41}$.

De nuevo en América, allí recibe el gobierno de Tucumán ${ }^{42}$, y, en fechas semejantes (1608), la noticia de la concesión de una nueva recompensa: el hábito de caballero de Alcántara, que también ha recibido poco tiempo ha su primo Antonio de Quiñones Mogrovejo ${ }^{43}$. Apenas sobrevivirá unos años a esta distinción, pues nos consta que falleció sólo y viudo en Santiago del Estero, donde otorgará testamento cerrado el 15 de febrero de 1622 ante el escribano Lizondo. Últimas voluntades que cuatro meses después serán abiertas aunque sus hijos aún deberán aguardar casi un año para conocer esta pérdida, pues se encuentran en España ${ }^{44}$.

Dejaba tres hijos: Fernando, que tomó el hábito de San Francisco, Lupercia, monja profesa en San Quirce de Valladolid, y Suero de Quiñones Osorio, su sucesor $^{45}$, quien cursó estudios de leyes en Valladolid ${ }^{46}$. Los bienes paternos, embargados para realizar la residencia, serán inventariados en Indias pero aún en 1625 el heredero de los mismos nada ha recibido, por lo que se queja muy amargamente $^{47}$. Por esas mismas fechas (hacia 1623), Suero ya ha desposado con

${ }^{40}$ A.G.I., Contaduría, 1811.

${ }^{41}$ La referencia es algunos años posterior y procede de su hijo y heredero (A.H.P.L., Protocolos de Gudino de Valcárcel, 1626, fol. 59 v.).

42 A.H.P.L., Protocolos de Gudino de Valcárcel, caja 9512, fol. 1; F. LóPEZ DE CARAVANTES (1987), Noticia general del Perú, II, Madrid: Atlas, p. 176.

${ }^{43}$ A.H.N., O.O.M.M., Alcántara, Exp. 1248.

${ }^{44}$ A.H.P.L., Protocolos de Gudino de Valcárcel, 1626, fol. 73 y ss.

45 A.H.P.L., Caja 9512, fs. 58 a 60 v.).

${ }^{46}$ Conocemos parte del inventario de libros y mobiliario que utilizó mientras residía en las casas de Miguel de Zamora durante su etapa de estudiante. Para beneficiar a su amigo Santiago de Alcoba decide donarle este material que detalla de manera preciosista (A.H.P.L., Protocolos de Gudino de Valcarcel, 1626, fs. 43 y ss.).

${ }^{47}$ Así, entrega poder para actuar al licenciado Alonso de Luances y al doctor Jorge de Figueroa, capellán del rey, ambos residentes en Madrid, así como a su propia hermana, Lupercia de Quiñones, que profesaba en San Quirce de Valladolid, como hemos referido. Advierte en este otorgamiento que: “...están enbargados todos los bienes que dexo en el Reyno de las Yndias, a causa de la residencia del dicho Don Luis mi padre, del dicho oficio de tal gobernador de la probincia de Tuquman, que esta sentenciada y apelada dicha sentencia en ella dada para ante Su Magestad y señores del 
María de Obregón y Velasco, hija del capitán Antonio de Obregón y Velasco, que sirvió con las armas al rey en Flandes y Milán y fue regidor de León amén de señor de San Martín de la Falamosa, Valdeconcha y Bustillos, y de Ana de Omaña y Quirós, hija de los señores de esta Casa leonesa de raigambre bajomedieval ${ }^{48}$. El linaje de la dama, que recomponemos en el árbol genealógico $5^{49}$, incluye personajes de la talla del obispo de Oviedo e Inquisidor Tristán Calvete, fundador del señorío de Valdeconcha por concesión de Carlos V, el señor de la Casa de los Velasco en Agustinos que fue secretario de Cámara de Felipe II y sus sucesores, Juan Núñez de Velasco ${ }^{50}$, o Juan de Robles, capitán en Indias, que gastó su vida allí durante más de veinte años, en Cuba y en la empresa de Hernán Cortés ${ }^{51}$.

Tres fueron los hijos de este matrimonio: Luis Antonio, Francisco Antonio y María de Quiñones, que acompañará a su tía Lupercia en el convento de San Quirce de Valladolid ${ }^{52}$. Todos ellos nacidos en España, pues Suero de Quiñones no abandonará la Península, prefiriendo ocuparse de sus señoríos y mayorazgos ibéricos antes que de la tierra de promisión americana. Sin embargo, la influencia de Indias lo impregna todo. Su comportamiento no deja de sorprender a sus vasallos, a los que exige que se quiten el sombrero a su paso y que se inclinen ante su esposa, siendo casi todos ellos, tal y como consta en los padrones de la época,

Consejo Supremo de las Yndias. Y aunque ha mucho tiempo que esta mandado traer la dicha residencia, no a venido al dicho Consejo de que se me sigue mucho daño respeto del dicho embargo y no me poder aprovechar de los dichos bienes..." (A.H.P.L., Caja 9512, f. 19).

${ }^{48}$ A.H.P.L., Protcolos de Gudino de Valcárcel, 1650, f. 16.

${ }^{49} \mathrm{Y}$ que ha sido posible recomponer a través de diversas fuentes como las ya mencionadas, a las que hemos de sumar varios documentos del capitán Tristán de Obregón y Cereceda, abuelo de nuestra dama (A.G.S., Contaduría de Mercedes, 500, 18; A.G.S., Patronato Real, caja 79, doc. 273)), o algunas otras referencias aportadas en su relación de servicios por el Maestre de Campo D. Bernardo Antonio de Valdés Obregón y Velasco, señor de las Casas de Obregón y Robles, y heredero de los restantes mayorazgos de su familia, como San Martín de la Falamosa (A.G.I., Indiferente, 127, N. 23).

${ }^{50}$ Cuyo mayorazgo finalmente heredará María de Obregón, esposa de Suero de Quiñones, señor de Quintanilla de Sollama, y que dará lugar a múltiples pleitos familiares (A.H.P.L., Protocolos de Gudino de Valcárcel, 1650, f. 16).

${ }^{51}$ Fallecido en 1531 y que dejaba, fruto de sus actividades en América desde 1505 en Cuba y que incluían su presencia junto a Cortés en la conquista de Méjico, diversos bienes y repartimientos que, a su muerte, son inventariados para que pueda disfrutar de ellos su viuda, María de Obregón, y sus hijos, de los que la dama es curadora (A.G.I., Santo Domingo, 1121, L.1, F.75R-75V; MEXICO, 1088,L.1BIS,F.73R-73V).

${ }^{52}$ A.H.P.L., Protocolos de Llamas de la Ribera, 1661, f. 22. 
hijosdalgo de sangre ${ }^{53}$. Se trata, sin duda, de una costumbre que vivió al otro lado del Atlántico y que desea trasladar a León, lo que provoca roces y enfrentamientos.

Su parte de la hacienda americana, que renta catorce mil pesos anuales, suele atravesar por numerosos baches en un camino plagado de problemas hasta España. Su tía, Mariana de Guzmán y Quiñones ${ }^{54}$, administraba aquellos bienes en su nombre, e influía en los testamentarios del antiguo gobernador de Tucumán manipulando a su favor las cuentas que debía rendir a su pariente, el señor de Quintanilla de sollamas. Esta falta de sintonía económica llevará al enfrentamiento directo entre ambos, agotadas las excusas de Mariana y aún de su hijo Pedro de Loaysa para ocultar su delito de apropiación indebida. Recurre Suero entonces, en 1641, a un pariente de su esposa, D. Alonso de Cereceda, fiscal de la Real Audiencia de la Ciudad de los Reyes, para que vigile de manera estrecha a su tía y primo $^{55}$. Ambos justificaban la tardanza en el pago basándose en las dificultades en las comunicaciones entre España e Indias, repletas las aguas altánticas de corsarios ingleses que atacaban a los galeones sin piedad. Pero incluso para esta excusatio encuentra respuesta Suero, conocedor de la realidad americana, que advierte a Cereceda que soliciten a Mariana y a Pedro que le remitan lo suyo de esta manera, para minimizar riesgos: “...se me ynbiassen cada un año la mitad de ellos en la admiranta de galeones, y la otra mitad en la capitán de galeones, que beniendo de esta forma registrados corriera por mi quenta el riesgo de la mar y no por quenta de la dicha señora doña Mariana... $" 56$.

53 A.H.P.L., Protocolos de Llamas de la Ribera, 1626.

${ }^{54}$ Aunque su parentesco es de primos, siguiendo las costumbres de la época, el más joven suele referirse al de más edad como tío.

55 No sólo para que exigiera explicaciones a los testamentarios de su padre sino, fundamentalmente y ante todo, para "...que cobrasse de mi señora doña Mariana de Guzman y Quiñones, mi tía, residente en la ciudad de Lima, viuda...los catorze mil pesos corrientes de ocho rales cada uno y para que ansimesmo cobrara de su merced dicha señora doña Mariana, mi tía, la plata, oro y las ropas qualesquiera ansi y otras que su merced ubiese cobrado...por quanto la dicha señora doña Mariana de Quiñones se quijaba en la cobrança de los dichos catorce mil pesos, que abia cobrado en nombre del dicho mi padre y de su haçienda, por...no poder inbiarmelos a España, avia tenido alguna quiebra, el dicho D. Alonso de Zereçeda se contente en mi nombre con la dicha señora doña Mariana en que me a de pagar por los dichos catorze mil y tresientos pesos que...en esta forma a estos reynos de España...para este presente año de 1644 y...saszesivamente en los quatro años siguientes...de los quales la dicha doña Mariana de Guzmán y Quiñones y el señor don Pedro de Loaysa y Quiñones su hijo hizieron scriptura a mi favor..." (A.H.P.L., Protocolos de Gudino de Valcárcel, 1641 y 1644).

${ }^{56}$ A.H.P.L. Protocolos de Gudino de Valcárcel y de Álvarez de Herrera, 1646-1647, s/f. 
Desafortunadamente para Suero, la cobranza se hundió para siempre, ya en las costas peruanas, ya en medio del Océano, rompiendo para siempre toda relación con la rama americana de la familia Quiñones Mogrovejo.

Pese a todo, la cuestión económica no impidió al señor de Quintanilla agotar su existencia de manera cómoda, pues además de la herencia española, los préstamos antaño realizados por su padre, el gobernador de Tucumán, al conde de Miranda, permitieron a su hijo y heredero gozar de los réditos que tal cuantía generaba ${ }^{57}$.

En 1651, fallece de forma repentina Suero de Quiñones dejando a sus hijos menores de edad ${ }^{58}$. Con él termina la aventura americana de su linaje que se inició en Perú antes incluso de la llegada a Lima del arzobispo Mogrovejo. Varias generaciones, diversos logros, algún que otro éxito económico, varias distinciones y hábitos de órdenes militares, amén de la división definitiva de la familia en dos, la rama americana y la española, rematan una historia que comienza en tiempos de Pizarro: la de los parientes de Santo Toribio Alfonso de Mogrovejo.

${ }^{57}$ A.H.P.L., Protocolos notariales, caja 9653, f. 12 y ss.

58 A.H.P.L., Protocolos notariales de Llamas de la Ribera, 1651, f. 44 y ss. 
Árbol Genealógico 1: Quiñones y Prado. Los antepasados de Francisco de Quiñones Villapadierna, cuñado de Santo Toribio de Mogrovejo.

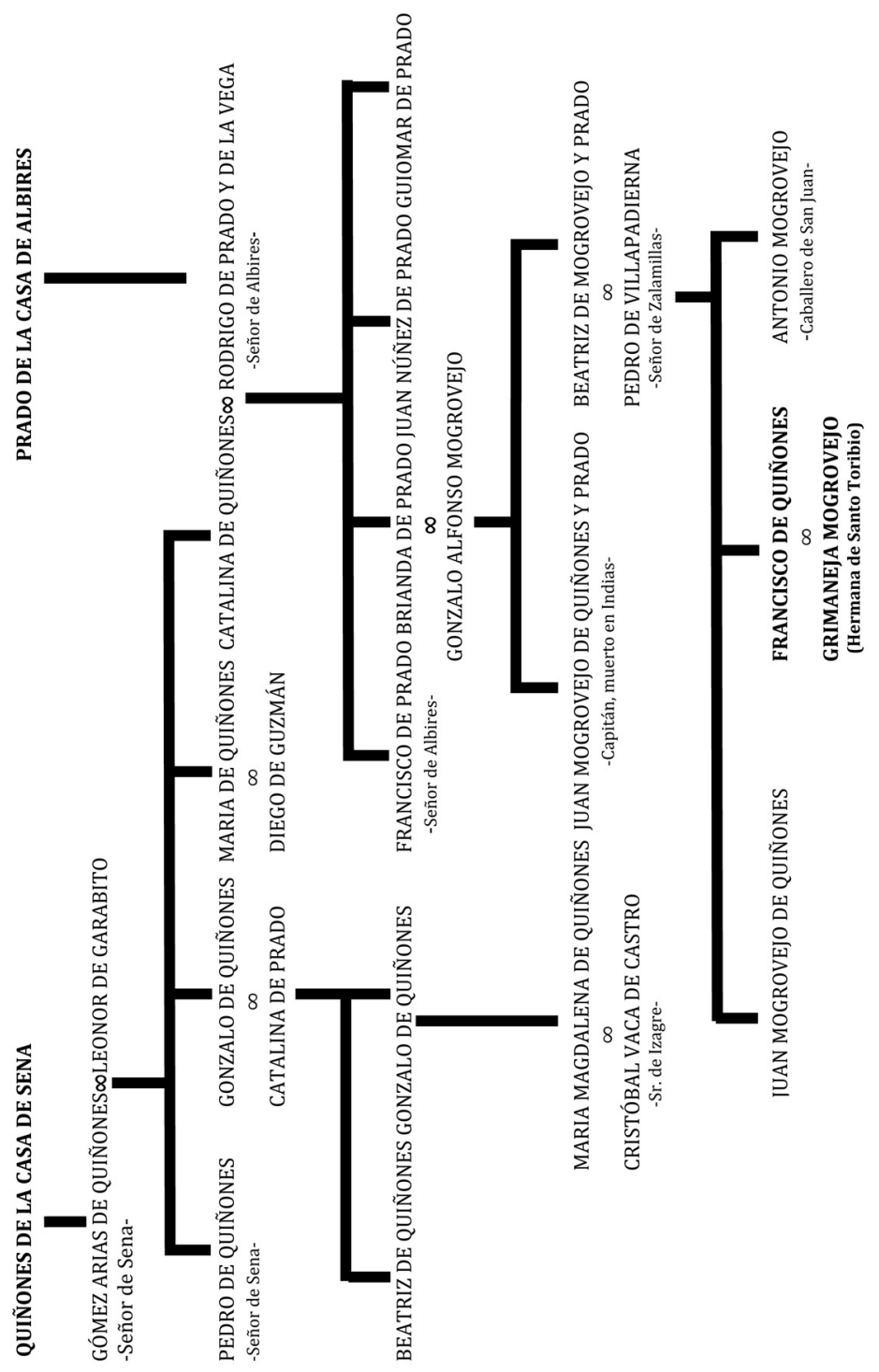


Árbol Genealógico 2: La estirpe Mogrovejo, el parentesco entre Francisco de Quiñones Villapadierna y Santo Toribio.

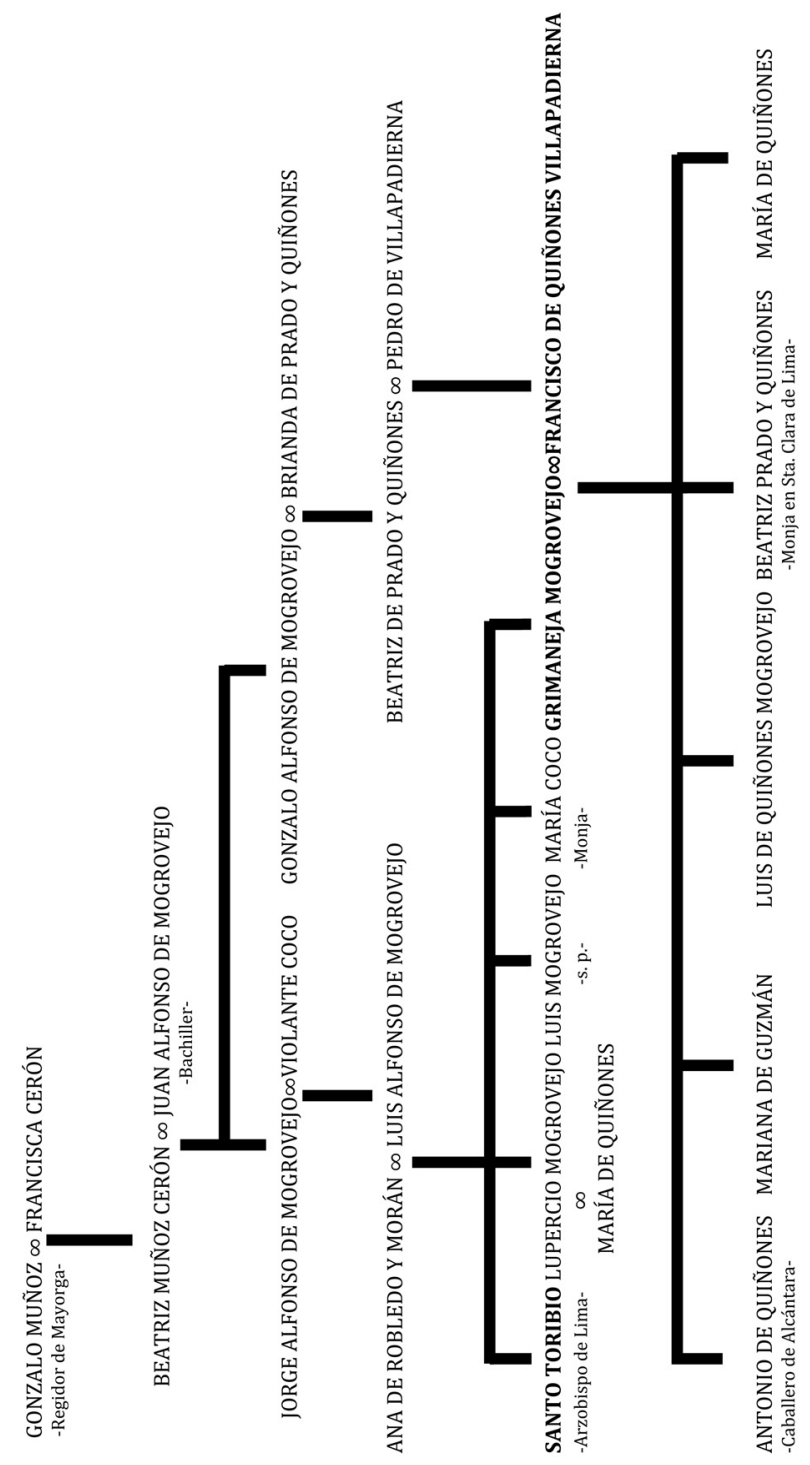


Árbol Genealógico 3: Descendencia de Francisco de Quiñones Villapadierna y Grimanesa Mogrovejo.

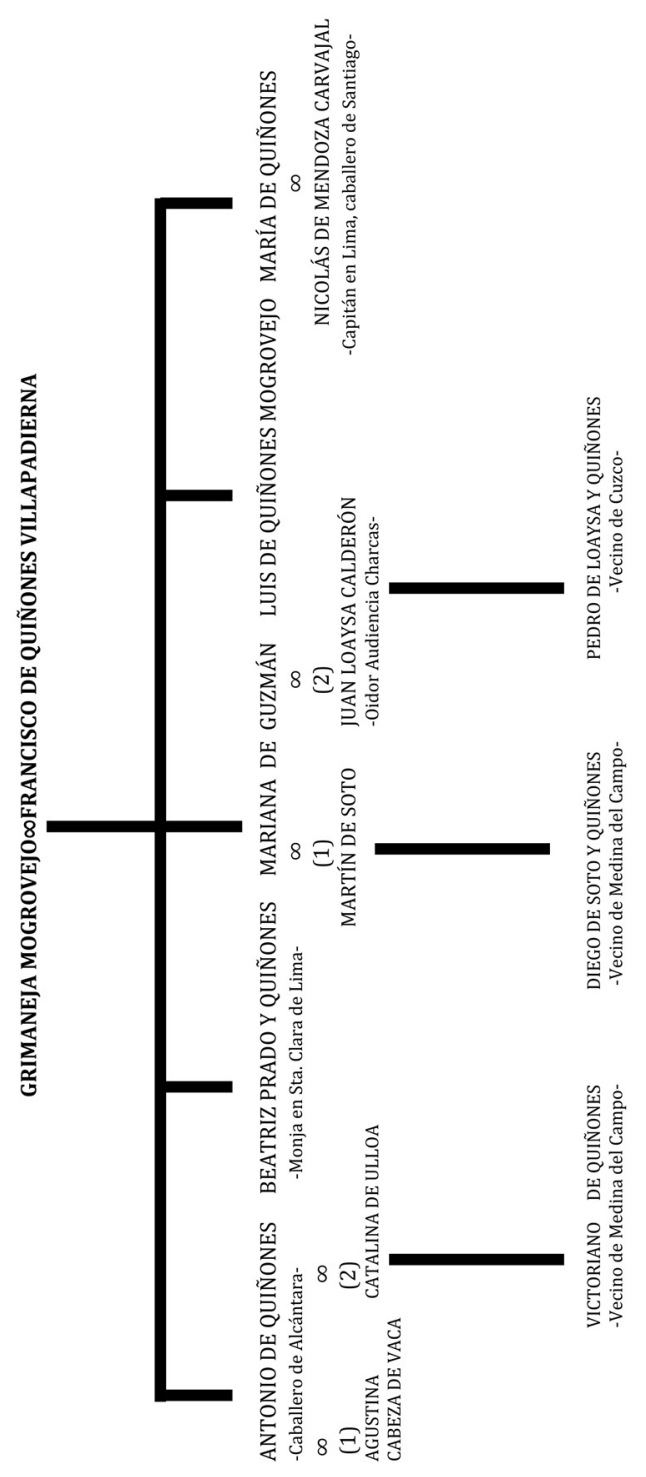


Árbol Genealógico 4: Los otros Quiñones Mogrovejo. Los descendientes de Luis Osorio de Quiñones, señores de Quiñones Quintanilla de Sollamas (León).

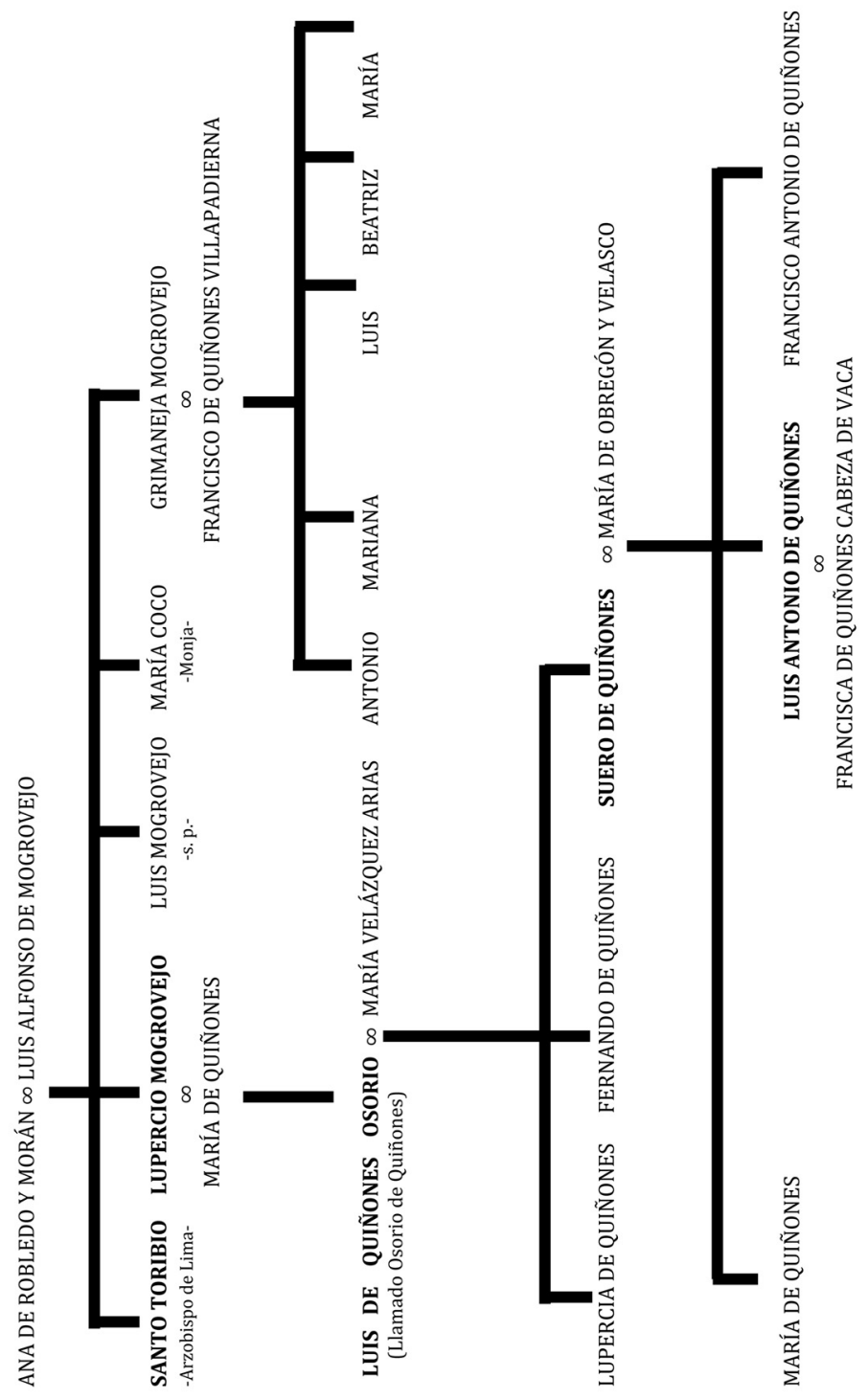


Árbol Genealógico 5: Los otros Quiñones Mogrovejo. Los descendientes de Luis Osorio de Quiñones, señores de Quiñones Quintanilla de Sollamas (León), y su parentesco con los Robles, Obregón y Cereceda.

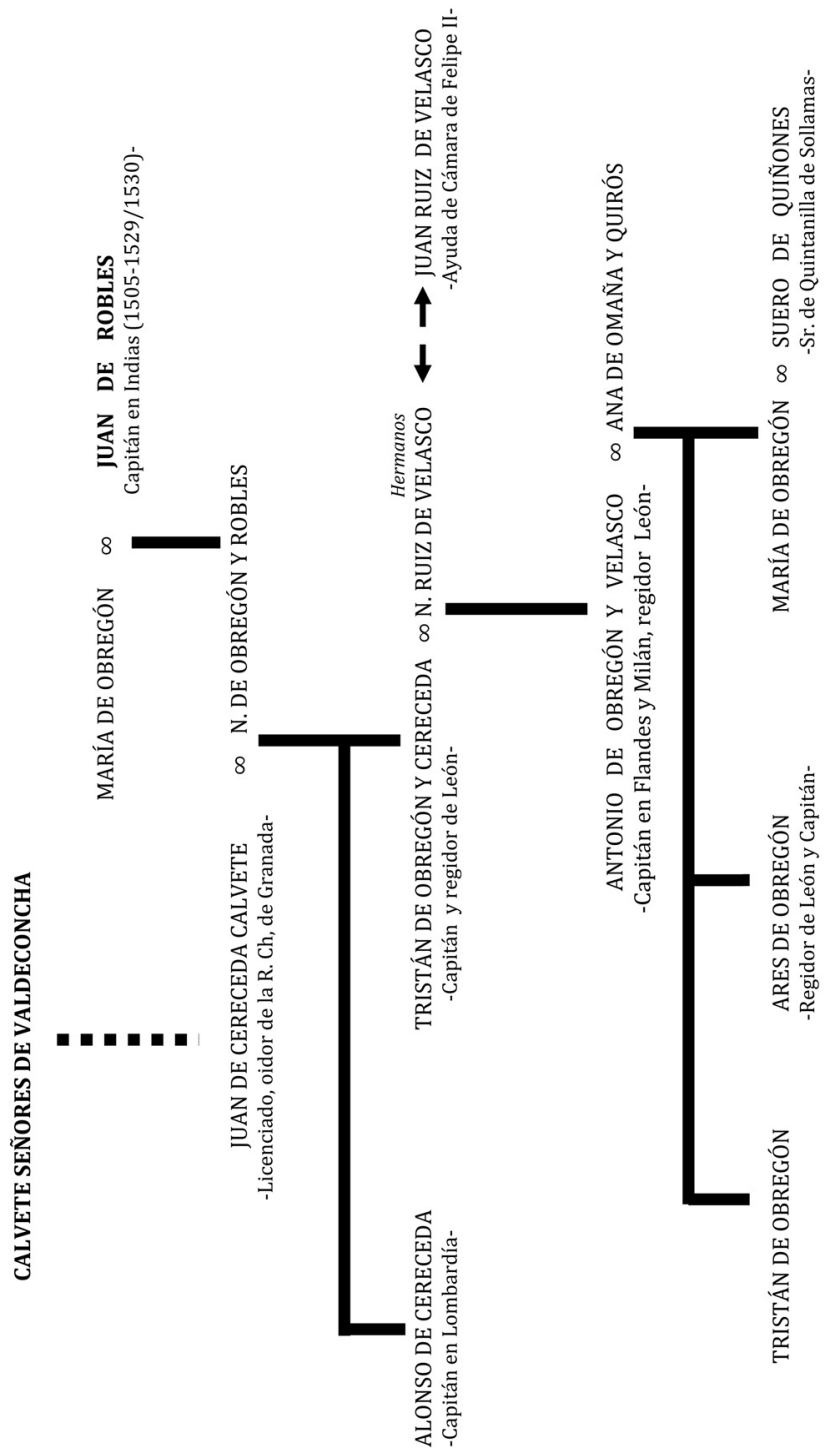

Señores de Valdeconcha: El Señorío segregado de la Orden de Calatrava por Carlos V a favor de Tristán Calvete, Inquisidor, Obispo de Lugo y, finalmente, de Oviedo. 
